\title{
Validation of quality of life questionnaire for patients with cancer - Indian scenario
}

\author{
Vidhubala E, Latha', Kannan Ravi $\mathbf{R}^{2}$, Mani $\mathbf{C S}^{2}$, Karthikesh $\mathrm{K}^{3}$, Muthuvel $\mathbf{R}^{1}$, \\ Surendran V 1 , Premkumari Rohini ${ }^{4}$ \\ Departments of Psycho-oncology, ${ }^{2}$ Surgical Oncology, ${ }^{4}$ Preventive Oncology, Cancer Institute (WIA), \\ Adyar, Chennai, 'Department of Psychology, University of Madras, Chennai, ${ }^{3}$ Department of Surgical \\ Oncology, Ramakrishna Institute of Oncology, Coimbatore, India
}

Correspondence to: Vidhubala E, E-mail: caninst@md2.vsnl.net.in

\section{Abstract}

BACKGROUND: Quality of Life (QOL) is an important health outcome measure in oncology. Given the underlying pressure of individual geo-political entities, a universal solution may not be applicable and hence there is a need to develop a regional tool and standardize the same to address the linguistic and socio-cultural factors. OBJECTIVE: To standardize a tool to assess the QOL of patients with cancer to suit the Indian scenario. MATERIALS AND METHODS: The samples were collected from the Cancer Institute (WIA), Chennai. Samples comprise of 400 patients with all sites and stages of cancer. Period: January 2001 to January 2002. Patients were in the age range of 41-60 years. Thirty-eight items were pooled from existing tools, reviews, and the field trial, by which face and factorial validity were established. Reliability of the tool was also tested. Correlation analysis was done to find out the relation between the domains of QOL. STATISTICS USED: Principal component method with varimax rotation was used. Spearmen product moment correlation and Cronbach alpha coefficient were used for reliability analysis. RESULTS: Ten factors emerged with Eigen values ranging from 8.55 to 1.10 and accounted for $62.6 \%$ of variance. The first factor contributed maximally, $22 \%$ of variance. The remaining nine factors contributed totally to $40 \%$ of the variance on QOL. The ten factors that emerged were psychological well being, self-adequacy, physical well being, confidence in self-ability, external support, pain, mobility, optimism and belief, interpersonal relationship and selfsufficiency and independence. The internal consistency using Cronbach alpha test was 0.90 and split-half reliability was 0.74 . CONCLUSION: The tool was found to be highly reliable and valid. It was feasible to administer it at clinical settings.

Key words: Cancer, Quality of life, Reliability, Validity

\section{Introduction}

Quality of Life is vital health outcome measure that is relevant to the care of cancer patients. There has been a shift in the management of the cancer patient from quantity to quality of survival in international research studies. The Quality of Life is a general term integrating several aspects of life such as physical, psychological, social, economical, spiritual, cognitional and sexual dimensions. A disturbance in any one aspect will in turn affect the other domains and this influences the overall QOL. ${ }^{[8]}$
One of the major areas of concern in Psycho-oncology is to understand the Quality of Life and to find ways of enhancing it. In Clinical Oncology, increasing importance is being given to the incorporation of Quality of Life as an outcome, in addition to other clinical endpoints.

The key objective measurement for QOL is the development of a 'quality of life' questionnaire. There are numerous studies on QOL tools, general and site specific. ${ }^{[1,2,3,4,6,7]}$ None of these tools however were developed to suit the Indian population except the 
QOL index,${ }^{[5]}$ which is suitable only for the normal population as described by the author.

Given the underlying pressure of individual geo-political entities, a universal solution may not be applicable and hence there is a need to develop a regional tool and standardize the same to address the linguistic and sociocultural factors.

Keeping this in mind, the present study is aimed at developing a standardized QOL questionnaire to suit the Indian cancer population, covering all domains of life.

\section{Methodology}

The samples were collected from Cancer Institute (WIA), Chennai, which is a Regional Cancer Center for Cancer Research and Treatment in the Ministry of Health and Family Welfare of the Government of India. It is an autonomous non-profit organization. Over 15,000 new patients and over 1,10,000 follow-up patients are seen annually from all over the country and also from South Asia and the Middle East. The period of the study extended from January 2001 to January 2002. Irrespective of the stage, site, age, education and treatment, all cancer patients were enrolled for the study and totally 400 samples were collected for standardizing the QOL tool. Samples were represented by more men $(58.2 \%)$ than women $(41.8 \%)$ and the age range was 17 - 90 years.

\section{Item pooling and validation of QOL scale}

European Organization for Research and Treatment of Cancer (EORTC) guidelines were followed to develop the QOL tool. To identify the relevant issues two methods were followed.

\section{Method I}

The relevant items were pooled from various sources like reviews of literature, existing QOL questionnaires, and interviews with patients and oncologists. In this process, totally 78 items were noted. By eliminating the overlapping issues and removing the items that were repetitive, totally 38 items were chosen.

\section{Method II}

In the second method, a pilot study was done initially where a set of questionnaires were administered to 30 patients. They were WHO-QOL-100, Jalowiec coping scale, Multidimensional Fatigue Inventory (MFI), McGill pain questionnaire, Affect balance scale, Optimisticpessimistic scale and the unstandardized QOL tool

Table 1: Process of standardization pilot study

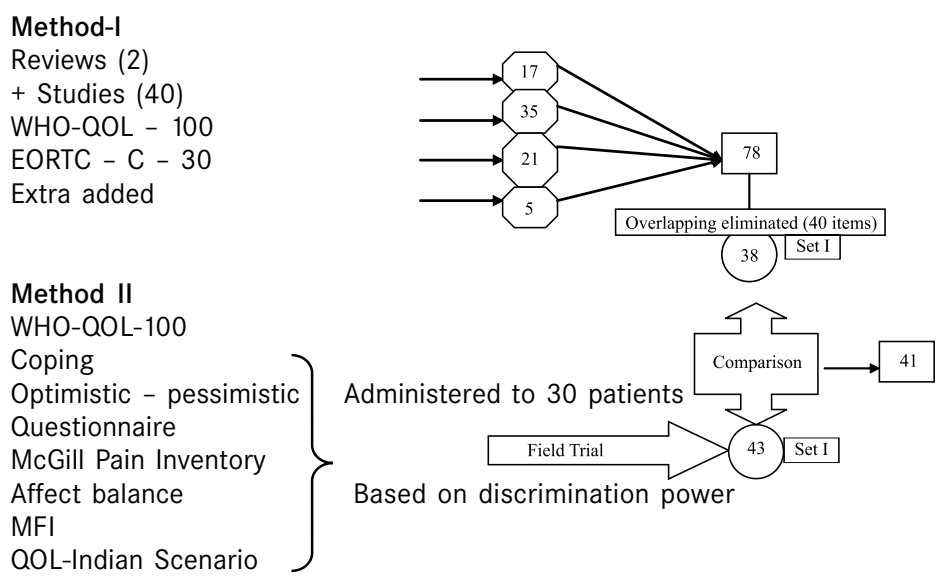

FACE VALIDITY (18 Experts)
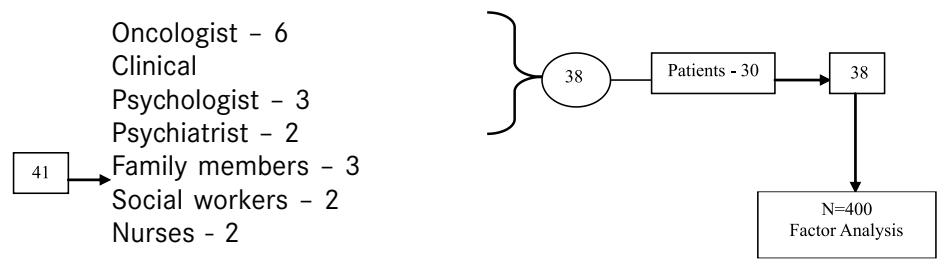
developed by the Cancer Institute Oncologists (Karthikesh et al. 1999). The responses of the above questionnaires were analyzed using their discrimination power. Only those items, which had high variability index, were included. Also, the items which were tapping similar issues and which had an overlap were eliminated. Finally 43 items were selected which were found to be relevant to the cancer patient's quality of life.

The 38 items chosen through method I was verified with 43 items, chosen from method II. Both set of measures depicted similar issues except 3 items. Adding these items, finally 41 items were retained for further validation.

\section{Face Validity}

Face validity, also called as content validity, is determined by a panel of experts who shall judge how well the measuring instrument meets the standards. After the pooling of items, the structured and comprehensively written items were given to 18 experts in medical and psychological fields, and people concerned with patients, for face validity. Judges ratings were analyzed for each item. The judges' concurrence ranged from $81 \%$ - 100\% for relevance, and 63\% $100 \%$ for clarity. The judges were asked to relate the comprehensiveness of the questionnaire to the globally applied quality of life concept. It was graded $100 \%$ for its comprehensiveness. Based on the suggestion of judges, ten questions were reframed and three were eliminated. Thus, finally 38 items were chosen for the study. Of the three eliminated questions, one was eliminated due to repetition, another due to low concurrence and the other due to irrelevance. The items were also administered to 30 patients to assess whether it could be applied to them or not. However, some older patients reported that issues such as sexual activities and work life as such would not be applicable to them but it may be applicable to others. All the 38 items were retained for factorial validation after the experts and patients concurrence.

\section{Scaling technique}

Likert type four point rating scale was added to elicit the responses from the respondents ranged from 1-4. For e.g. Do you feel depressed?

$\begin{array}{cccc}1 & 2 & 3 & 4 \\ \text { Very much } & \text { Moderate } & \text { A little } & \text { Not at all }\end{array}$

A few items were scored in reverse in order to make the questionnaire unidirectional and to yield a global QOL score. For example, Are you satisfied with your working capacity?' If the answer is very much, it will be scored inreverse i.e. 4 as 1 and 1 as 4 to get positive QOL index.

The direct and reverse scoring items are given below. Direct Scoring: 1, 2, 3, 5, 6, 7, 8, 11, 14, 17, 18, 16, $19,21,26$ and 32 .

Reverse Scoring: 4, 9, 10, 12, 13, 15, 20, 22, 23, 24, $25,27,28,29,30,31,33,34,35,36$,

37 and 38 .

\section{Statistical analysis}

Statistical analysis was performed using the Statistical Package for Social Sciences (SPSS) version 10.0. By employing the Kaiser-Meyer-Olkin (KMO) and Bartlett's test of sphericity, the sampling adequacy was tested. The extraction method used was principal component analysis (Nunnally and Bernstein 1994) with varimax rotational method. Factor loading of less than 0.40 was disregarded. Reliability of the tool was tested using the Split-half reliability method and Cronbach alpha co-efficient test.

\section{Table 2: Initial solutions based on principal component analysis and component loadings}

\begin{tabular}{lllll}
\hline Factors & Eigen value & $\begin{array}{l}\text { Percentage } \\
\text { of variance }\end{array}$ & $\begin{array}{c}\text { Cumulative } \\
(\%)\end{array}$ & Communality \\
\hline 1 & 8.55 & 22.5 & 22.5 & 0.647 \\
\hline 2 & 3.15 & 8.28 & 30.8 & 0.653 \\
\hline 3 & 1.18 & 6.17 & 56.7 & 0.671 \\
\hline 4 & 1.83 & 4.81 & 35.6 & 0.591 \\
\hline 5 & 1.56 & 4.12 & 39.7 & 0.504 \\
\hline 6 & 1.48 & 3.90 & 43.6 & 0.430 \\
\hline 7 & 1.32 & 3.47 & 47.1 & 0.331 \\
\hline 8 & 1.31 & 3.46 & 50.5 & 0.527 \\
\hline 9 & 1.12 & 2.96 & 59.7 & 0.217 \\
\hline 10 & 1.10 & 2.89 & 62.6 & 0.407 \\
\hline
\end{tabular}

\begin{tabular}{|c|c|c|}
\hline \multicolumn{3}{|c|}{ Factor 1: Psychological well being (six items) } \\
\hline Item & Loading & Description \\
\hline 17 & 0.819 & $\begin{array}{l}\text { Does the feeling of sadness or depression } \\
\text { interfere with your everyday functioning? }\end{array}$ \\
\hline 18 & 0.786 & $\begin{array}{l}\text { Do you feel very lonely or remote from } \\
\text { other people? }\end{array}$ \\
\hline 16 & 0.771 & Do you feel depressed? \\
\hline 32 & 0.471 & $\begin{array}{l}\text { Do you feel that your physical condition has } \\
\text { resulted in reduced economical status? }\end{array}$ \\
\hline 14 & 0.455 & $\begin{array}{l}\text { Do you feel that you have too much time } \\
\text { but nothing important to do? }\end{array}$ \\
\hline 8 & 0.356 & $\begin{array}{l}\text { Do you feel you are physically performing } \\
\text { less than what you want to do? }\end{array}$ \\
\hline
\end{tabular}




\section{Results}

As the primary objective of this study was to identify the nature of the factors underlying the set of measures in the questionnaire, the data was subjected to factor analysis. This analysis was typically used to construct a scale and simultaneously identify the concepts.

The KMO value of 0.83 and the high significant level ( $\mathrm{p}$ value $=0.00)$ in Bartlett's Test of Sphericity showed that the sample was adequate for factor analysis.

Ten factors emerged with Eigen values ranging from 8.55 to 1.10 . Ten factors accounted for $62.6 \%$ of variance. The first factor contributed maximally $22 \%$ of variance. The remaining 9 factors contributed totally $40 \%$ of the variance on QOL. The "\% of Variance" gives the percent of variance accounted for by each specific factor or component, relative to the total variance in all the variables. The Eigen value is the ratio of the between groups sum of squares to the within groups sum of squares. The largest Eigen value corresponds to the eigenvector in the direction of the maximum spread of the groups means. The second largest eigen value corresponds to the eigen vector in the direction that has the next largest spread, and so on. Eigen value shows the purity of a variance contributed by a factor or component. Eigen value of 1 is usually acceptable, hence only those factors were included. The communality factor indicated a significant

\begin{tabular}{|c|c|c|}
\hline \multicolumn{3}{|c|}{ Factor 2: Self-adequacy (five items) } \\
\hline Item & Loading & Description \\
\hline 28 & 0.683 & $\begin{array}{l}\text { Are you satisfied with your working } \\
\text { capacity? }\end{array}$ \\
\hline 15 & 0.603 & $\begin{array}{l}\text { Are you comfortable attending functions as } \\
\text { usual? }\end{array}$ \\
\hline 27 & 0.537 & $\begin{array}{l}\text { Are you satisfied with the way your body } \\
\text { looks? }\end{array}$ \\
\hline 35 & 0.491 & $\begin{array}{l}\text { Are you satisfied with your present health } \\
\text { status? }\end{array}$ \\
\hline 36 & 0.468 & Are you satisfied with your overall QOL? \\
\hline
\end{tabular}

\begin{tabular}{|c|c|c|}
\hline \multicolumn{3}{|c|}{ Factor 3: Physical well being (six items) } \\
\hline Item & Loading & Description \\
\hline 7 & 0.678 & Do you feel you need more rest? \\
\hline 22 & 0.549 & Are you satisfied with your present sex life? \\
\hline 6 & 0.352 & Do you have any sleep problems? \\
\hline 11 & 0.640 & Do you lose your temper and regret it? \\
\hline 5 & 0.638 & Is your bowel movement affected? \\
\hline 26 & 0.571 & $\begin{array}{l}\text { Do you have difficulty in remembering } \\
\text { things? }\end{array}$ \\
\hline
\end{tabular}

\begin{tabular}{lll}
\hline \multicolumn{2}{l}{ Factor } & 4: Confidence in self-ability (four items) \\
\hline Item & Loading & Description \\
\hline 23 & 0.793 & $\begin{array}{l}\text { Do you feel confident that you are able to } \\
\text { manage your financial needs at any } \\
\text { situation? }\end{array}$ \\
\hline 24 & 0.639 & $\begin{array}{l}\text { Are you confident that you are able to fulfill } \\
\text { your family needs? }\end{array}$ \\
\hline 33 & 0.485 & $\begin{array}{l}\text { Are you satisfied with the responsibilities } \\
\text { you have already fulfilled? }\end{array}$ \\
\hline 25 & 0.405 & $\begin{array}{l}\text { Are you able to concentrate on your daily } \\
\text { activities? }\end{array}$ \\
\hline
\end{tabular}

loading and common factor variance and unique variance in the structure. Even though some solutions had minimal loading of items, they were included to explain the underlying constructs.

The following table represents the Eigen values and contribution to total variance. The communality $\left(h^{2}\right)$ indicates the common variance attributed to each factor, which ranges from 0.21 to 0.65 . Theoretically, many aspects of a person's life influences Quality of Life, and therefore the researcher used as many factors, which significantly contributed to variance.

Items within each factor were analyzed and were named based on the item description. There were totally 38 items within 10 factors. These factors and its loadings are explained in the following tables.

The first factor with an Eigen value of 8.55 emerged significant with six items. This factor contributed a variance of $22.5 \%$ to the total variance. The factor loadings ranged from 0.82 to 0.36 . The items in this

\begin{tabular}{|c|c|c|}
\hline \multicolumn{3}{|c|}{ Factor 5: External support (four items) } \\
\hline Item & Loading & Description \\
\hline 37 & 0.748 & $\begin{array}{l}\text { Do you feel the doctor is co-operative and } \\
\text { gives enough information whenever you } \\
\text { need? }\end{array}$ \\
\hline 38 & 0.714 & $\begin{array}{l}\text { Do you feel the given treatment is adequate } \\
\text { for you? }\end{array}$ \\
\hline 30 & 0.638 & $\begin{array}{l}\text { Do you get the kind of support you need } \\
\text { from your spouse and family members? }\end{array}$ \\
\hline 31 & 0.619 & $\begin{array}{l}\text { Do you get the kind of support you need } \\
\text { from your friends and relatives? }\end{array}$ \\
\hline
\end{tabular}

\begin{tabular}{|c|c|c|}
\hline \multicolumn{3}{|c|}{ Factor 6: Pain (three items) } \\
\hline Item & Loading & Description \\
\hline 1 & 0.778 & Do you experience any pain at present? \\
\hline 2 & 0.723 & $\begin{array}{l}\text { Does your pain interfere in your day-to-day } \\
\text { activities? }\end{array}$ \\
\hline 3 & 0.494 & How dependent are you on medication? \\
\hline
\end{tabular}


factor underlined the significance of psychological well being. Item 17 had the highest loading of 0.82 . Sadness or depression interfering with everyday functioning, feeling lonely or remote, feeling depressed, the physical condition reducing economic status, and feeling of low performance compared to one's ability are described in the first factor. All the items mentioned, referred to psychological feelings. The common variance is high (0.64) showing the underlying communality. Hence, this factor was named as "Psychological Well-being".

The second factor has five items with significant loading, which ranged from 0.68 to 0.46 . This factor contributed a variance of $8.28 \%$ to the total variance with an Eigen value of 3.15. The items described the individual's feelings of adequacy towards working capacity, attending functions, body image, health status and overall well-being. The communality of 0.65 indicates that the items share a common variance. The higher score on these items indicates satisfaction, sense of worth, ability and confidence and thus this factor was named as "Self-Adequacy".

The Eigen value of the third factor was 1.18. The variance contributed by this factor was $6.17 \%$. The six items in this factor describes sleep problems, rest, satisfaction with sex life, losing temper and regretting, problems in bowel movements and dependency on medication. The loading ranged from 0.67 to 0.35 . The communality was 0.67 showing high common variance. The responses to these items in terms of higher scores indicate freedom from the abovementioned symptoms and also physical comfort and satisfaction. Hence, the factor was named as "Physical Well-being".

\begin{tabular}{|c|c|c|}
\hline \multicolumn{3}{|c|}{ Factor 7: Mobility (two items) } \\
\hline Item & Loading & Description \\
\hline 12 & 0.812 & $\begin{array}{l}\text { Are you able to interact with people as } \\
\text { usual? }\end{array}$ \\
\hline 13 & 0.801 & $\begin{array}{l}\text { Are you able to move around (physical) as } \\
\text { usual? }\end{array}$ \\
\hline \multicolumn{3}{|c|}{ Factor 8: Optimism and belief (four items) } \\
\hline Item & Loading & Description \\
\hline 9 & 0.656 & $\begin{array}{l}\text { Do you always expect good things to } \\
\text { happen? }\end{array}$ \\
\hline 10 & 0.654 & $\begin{array}{l}\text { How important do you feel yourself at } \\
\text { present? }\end{array}$ \\
\hline 4 & 0.446 & Is your appetite normal? \\
\hline 34 & 0.429 & $\begin{array}{l}\text { To what extent does your personal beliefs/ } \\
\text { religious faith give you the strength to face } \\
\text { difficulties? }\end{array}$ \\
\hline
\end{tabular}

The fourth factor has four items contributing a variance of $4.81 \%$ to the total variance with an Eigen value of 1.83. The items describe one's efficacy in managing financial needs, fulfilling family needs, satisfaction in fulfilling responsibilities and ability to concentrate on daily activities. These items refer to the satisfaction and confidence that a person has in fulfilling his/her role as a family member, social and work roles, and effectively meeting the demands placed on them. The communality of 0.59 indicates the items share a common variance. Thus, this factor was termed as "Confidence in self-ability".

The fifth factor has four items with an Eigen value of 1.56 and contributed a variance of $4.12 \%$. These items describe the support of doctor, informational support, treatment adequacy, support of family, spouse, friends and relatives. All the items are positively stated. Hence, higher scores indicate greater support received and also satisfaction with the support. The communality was 0.50 indicating $50 \%$ of the common variance within items. Since, it measures the satisfaction with various supports, it was named "External Support".

The sixth factor has three items with significant positive loading. This factor contributes a variance of $3.90 \%$ to the total variance with an Eigen value of 1.48. The item 1 and 2 describes the experience of pain and its interference in day-to-day activities and item 3 describes dependency on medication. This dimension was more related to the clinical condition and it is a significant factor contributing to the overall differences in QOL. The communality was 0.43 , which indicates the common variance within items to be moderate. Hence, this factor was named "Pain".

The seventh factor consists of item 12 and 13 with a very high loading of 0.81 and 0.80 respectively. This factor has an Eigen value of 1.32 and contributes a

\begin{tabular}{|c|c|c|}
\hline \multicolumn{3}{|c|}{ Factor 9: Interpersonal relationship (two items) } \\
\hline Item & Loading & Description \\
\hline 21 & 0.766 & $\begin{array}{l}\text { Has your physical condition/medical } \\
\text { treatment interfered with your sex life? }\end{array}$ \\
\hline 29. & 0.391 & $\begin{array}{l}\text { How satisfied are you about your } \\
\text { relationship with your family? }\end{array}$ \\
\hline
\end{tabular}

\begin{tabular}{lll}
\hline $\begin{array}{l}\text { Factor } \\
\text { (two }\end{array}$ items) & Self-sufficiency and independence \\
\hline Item & Loading & Description \\
\hline 20 & 0.653 & $\begin{array}{l}\text { Do you feel free to share your problems } \\
\text { with your family members? }\end{array}$ \\
\hline 19 & -0.518 & $\begin{array}{l}\text { Do you need any assistance to do your day- } \\
\text { to-day activities? }\end{array}$ \\
\hline
\end{tabular}


Table 3: Showing reliability of QOL questionnaire

\begin{tabular}{lc} 
Method & Coefficient of correlation \\
\hline Cronbach alpha & 0.90 \\
\hline Split-half reliability & 0.85 \\
\hline Part I (19 items) & 0.85 \\
\hline Part II (19 items) between forms & 0.74 \\
\hline
\end{tabular}

variance of $3.47 \%$ to the total. The items describe the patient's ability to interact and move around as usual. This factor was named "Mobility". Mobility means functional ability that includes the freedom of movement and ability to perform social roles and also the capacity to execute these functions. The lowest communality value of 0.33 indicates that the factor represents the social or physical 'mobility' and they may not relate to each other.

The four items in eighth factor contributes a variance of $3.46 \%$ with an Eigen value of 1.31. The items on this factor describe a positive outlook characterized by always expecting good things to happen, self-importance and personal beliefs and/or religious faith. This factor almost borders on the spiritual dimension of health and QOL. The communality was 0.52 indicating the items share a common variance. Based on these positive loadings, this factor was named as "Optimism and Belief “. Item No.4 seems to be a physical aspect, but here it denotes optimism about health for this population. Hence it was loaded in this domain and retained as it is.

The ninth factor contributes a variance of $2.96 \%$ with an Eigen value of 1.12. The two items in this factor describe the interference of medical treatment in sexual life and in the relationship with family members. The items 21 and 29 were loaded at 0.76 and 0.39 respectively. The communality of 0.21 indicates both the items share few unique variances. However, the satisfaction in relationship and the disease condition differentially influence the need for intimacy (Love) and the need for belongingness (Affection). Hence, this factor was named as "Interpersonal relationship".

The tenth factor contributes a variance of $2.89 \%$ with an Eigen value of 1.10. This factor has two items. The item 20 has a positive loading of 0.65 and item 19 has a negative loading of -0.51 . The common factor variance of 0.40 indicates that the items within this component share minimal unique characteristics. These items show if the patient freely shares his or her problems with his or her family or not and also whether he or she require assistance in daily activities.
This factor was named as "Self-sufficiency and Independence".

Thus, the QOL scale had 38 items with 10 factors namely, Psychological well-being, Self-adequacy, Physical well-being, Confidence in self-ability, External support, Pain, Mobility, Optimism and belief, Interpersonal relationship and Self-sufficiency and Independence. These factors have every aspect of an individual's life relevant to the cancer envisaged. The face validity and factorial validity were thus established.

\section{Reliability}

Reliability analysis for the questionnaire was carried out using Alpha coefficient and Guttman Split-half reliability method. The Cronbach alpha of 0.90 and Split-half reliability of 0.74 showed the reliability of the tool.

\section{Interpretation of QOL scale}

The maximum score for the questionnaire was 152 and the minimum score was 38 . To establish norms for interpretation, the outlier and the extreme values were eliminated and this reduced the sample size from 400 to 374 .

The skewness value was found to be -.410 and hence it was evident that the sample size was normally distributed. Therefore, the percentiles were taken into consideration for establishing the cut off points for the Quality of Life Scale.

Based on the percentiles, the norms for the scale were established as follows.

$$
\begin{array}{ll}
88 \text { and below } & \text { - Significantly poor QOL } \\
89-108 & - \text { Below average QOL } \\
109-132 & - \text { Average QOL } \\
133-144 & \text { - Above average QOL } \\
\text { Above } 144 & - \text { Significantly High QOL }
\end{array}
$$

\section{Conclusion}

The validity was established through face/content validity and construct, also called factorial validity. Internal consistency reliability of the module was satisfactory (Chronbach's a $=0.90$ ). This is the selfadministered questionnaire where the importance has been given to the patient's satisfaction in different aspects of life. It can be concluded from the present study that QOL is a multidimensional construct with many factors within it. Quality of Life is a multidimensional concept and the dimensions that 
emerged are Psychological well-being, Self-adequacy, Physical well-being, Confidence in self-ability, External support, Pain, Mobility, Optimism and belief, Interpersonal relationship and Self-sufficiency and Independence. This tool was less time consuming (12 15 minutes) and hence it was feasible to administer at clinical settings.

\section{Limitation}

The study was confined to a single Institution. Further standardization of the Quality of Life tool across different cancer populations and cultures are needed. Multi - center trial will help in developing a comprehensive, sensitive tool for QOL.

\section{Acknowledgement}

Mr. F.U. John Paul for assistance in writing and editing the manuscript; Mr. Krishnamurthy for helping in data extraction and Ms. P. Saritha for her secretarial assistance.

\section{References}

1. Aaronson NK. Methodologic issues in assessing the QOL of cancer patients. Cancer 1991;67:844.

2. Aaronson NK, Bullinger M, Ahamedzai S. A modular approach to Quality of Life assessments in cancer clinical trials. Recent results. Cancer Research 1988;111:231-49.

3. Bjordal K, Kaasa S. Psychometric validation of the EORTC Core quality of life Questionnaire, 30item version and a diagnostic specific module for a head and neck cancer patients. Acta Oncologica 1992;33:879-85.

4. Karnofsky DA, Burchenal JH. The Clinical evaluation of chemotherapeutic agents in cancer. In: CM Mc leod, editor. Evaluation of chemotherapeutic agents. New York: Columbia University Press; 1949.

5. Latha, Karthikeyan S. Quality of Life- A preliminary study. Indian Journal of Applied Psychology 1998;45:1 \& 2.

6. Rathmell AJ, Ash DV, Howes M, Nicholls. Assessing quality of life in patients treated for advanced head and neck cancer. Journal of Clinical Oncology 1991;3:10-6.

7. Schipper H, Clinch J, Mc Murray A, Levitt M. Measuring the quality of life of cancer patients: The Functional Living Index-Cancer Development and Validation. Journal of Clinical Oncology 1984;2:472.

8. In: Taylor, Shelley E, editor. Health Psychology. $3^{\text {rd }}$ edn. New York: Mc Graw-Hill, Inc; 1995. 